\title{
When It Helps, When It Hurts: Preliminary Results of Relationship Enhancement Education and The Hold Me Tight Program
}

\author{
Adam R. Fisher' ${ }^{1}$, Marie F. Stokey ${ }^{1}$, Hiroshi M. Sasaki ${ }^{2}$, Thomas L. Sexton ${ }^{1}$ \\ ${ }^{1}$ Indiana University, Bloomington, USA \\ ${ }^{2}$ University of the West, Rosemead, USA \\ Email: adrofish@indiana.edu
}

Received 19 June 2014; revised 12 July 2014; accepted 4 August 2014

Copyright (C) 2014 by authors and Scientific Research Publishing Inc.

This work is licensed under the Creative Commons Attribution International License (CC BY). http://creativecommons.org/licenses/by/4.0/

(c) () Open Access

\begin{abstract}
Relationship education such as self-help and group interventions may be helpful for couples seeking to improve their relationships. This outcome study sought to provide preliminary data on the effectiveness of two interventions for couples, comparing the self-help book Hold Me Tight: Seven Conversations for a Lifetime of Love, to the 8-week relationship course, The Hold Me Tight Program: Conversations for Connection, which includes reading the book at home. Results suggest that reading the book alone may lead to positive change, attending the course in addition to reading the book may not result in as much change, and that participation in the course may have a potentially negative effect for less happy couples in the area of dyadic consensus. Results signify the importance of further research to understand the potential benefits as well as iatrogenic effects of relationship education.
\end{abstract}

\section{Keywords}

Self-Help, Psychoeducation, Relationship Education, Emotionally Focused Therapy

\section{Introduction}

Emotionally focused couple therapy (EFT), has been found through repeated studies to be effective for moving couples out of distress (Johnson, Hunsley, Greenberg, \& Schindler, 1999). In comparison with behavioral marital therapy (BMT), EFT may be more effective for treating moderate levels of marital distress (Wood, Crane, Schaaljie, \& Law, 2005). Chambless and Ollendick (2001) have designated EFT as a "probably efficacious" empirically supported treatment for moderate levels of marital discord. However, couples may not always have ac- 
cess to clinicians trained in EFT or other evidence-based practices. Even when treatment options are available, only $36 \%$ of couples seek outside help within the first five years of marriage, typically through books and psychotherapy (Doss, Rhoades, Stanley, \& Markman, 2009). Self-help and psychoeducation may be a useful tool for couples to improve their relationships, and to address related concerns such as anxiety and depression (Mains \& Scogin, 2003), particularly when access to psychotherapy is limited due to financial concerns or a lack of services (Ellis, 1993).

Although consumers may hope that the books will help, there is little evidence supporting the effectiveness of most self-help books (Norcross et al., 2003). With relationship education programs being more accessible to religious (Doss et al., 2009) and middle-class couples (Ooms \& Wilson, 2004), underserved populations may not have access to the help they seek (Wetzler, Frame, \& Litzinger, 2011). Sue Johnson, one of the originators of EFT, created educational versions of EFT that could be used by the general public (Johnson, 2008). Specifically, Johnson promotes the book Hold Me Tight: Seven Conversations for a Lifetime of Love, as intended for couples, whether they are happy or distressed, with the exceptions being relationships involving abuse, ongoing extradyadic relationships, and serious addictions. Although over $95 \%$ of the thousands of new self-help literature that are published every year have no empirical support (Rosen, 1993), findings do suggest that some self-help programs are effective (Norcross et al., 2003). Given that self-help literature may be useful, and that some find it easier to work on personal issues through books rather than through interactions with groups (Ellis, 1993), would relationship self-help such as Hold Me Tight be effective in improving relationships?

\subsection{When Education Helps}

Self-help books may be helpful for some people (Halliday, 1991), especially from the perspective of clinicians, who were found to view about one-fifth of popular self-help books as "very helpful" (Norcross et al., 2000, 2003). Although many self-help books have little research support and make exaggerated claims, a study of over a thousand psychologists found that most feel self-help is at least somewhat helpful for clients more than $70 \%$ of the time (Norcross et al., 2003). Psychoeducational interventions for couples, such as a group for couples that focuses on issues such as conflict resolution, may also be helpful for improving relationships (Cummings, Faircloth, Mitchell, Cummings, \& Schermerhorn, 2008). A meta-analysis of 117 studies on marital and relationship education psychoeducation suggests that these programs often result in moderate positive effects (Hawkins, Blanchard, Baldwin, \& Fawcett, 2008). Four marital enrichment programs were considered by Jakubowski et al. (2004) to be efficacious.

Group interventions for couples may also serve to increase satisfaction in relationships (Halford, Moore, Wilson, Farrugia, \& Dyer, 2004; Bodenmann \& Shantinath, 2004; Long, Angera, Carter, Nakamoto, \& Kalso, 1999), reduce symptoms of depression and anxiety (Pomeroy, Green, \& Laningham, 2002), improve relationships for couples in which one partner has been diagnosed with a personality disorder (Bout, Sytema, \& Rankin, 2008), effectively help couples in inpatient settings (Sytema \& Bout, 2006), and decrease dating violence (Gardner, Giese, \& Parrott, 2004). Daire et al. (2012) also found that Hispanic couples perceived relationship education to be beneficial for themselves and their families. Despite these apparent benefits of group interventions for couples, improvements in areas such as communication and forgiveness may be diminished at follow-up (Sells, Giordano, \& King, 2002).

\subsection{When Education Hurts}

Self-help and psychoeducation may also be harmful (Crawford, 2004), and the possible negative effects of many of these interventions have not been studied (Ellis, 1993), and those that have tend to be less effective for more severe issues (Mains \& Scogin, 2003). Crawford (2004) reported that many "best-selling” self-help interventions for relationships promote rigid gender stereotypes, and offer potentially damaging advice to women. Ellis (1993) adds that the idea that fixing problems is a quick and easy process, which is commonly promoted by some selfhelp books, may result in a worsening of problems. Due to a lack of specificity regarding what types of people and problems they are meant to address, self-help interventions may also be incorrectly applied by many consumers (Rosen, 1987), and are not equally effective for every problem (Wilson \& Cash, 2000).

Additional outcome research on psychoeducation and self-help for couples in is needed. The current study seeks to add to the existing research on self-help and psychoeducation for couples by providing preliminary data on the effectiveness of the book, Hold Me Tight: Seven Conversations for a Lifetime of Love, and the related re- 
lationship class, The Hold Me Tight Program: Conversations for Connection, as well as by outlining areas for future research on relationship education.

\section{Method}

\subsection{Participants}

20 adults (10 couples) in a small Midwestern city participated in the study, after responding to flyers placed around the city and at a local counseling center, and newspaper advertisements. Most of the participants identified themselves as White, with a few identifying as either multiracial or European. Their average age was 33.3 years. All of the participants reported that they were in monogamous, heterosexual relationships. 18 of the participants indicated that they were married. Although participants were not paid for their participation in the study, each couple was provided with one copy of the book free of charge.

\subsection{Materials}

Materials used in the study included the relationship self-help book, Hold Me Tight: Seven Conversations for a Lifetime of Love (Johnson, 2008), and facilitator's guide and other materials for the relationship course, The Hold Me Tight Program: Conversations for Connection (Johnson, 2010), which supplements the book with didactic presentations and group discussion, video, in-session worksheets, and homework assignments.

\subsection{Measures}

The measures used in the study were the Dyadic Adjustment Scale (Spanier, 1976), and the Trust Scale (Rempel, Holmes, \& Zanna, 1985). The Dyadic Adjustment Scale (DAS) consists of 32 items, which are added together to provide a scoring range from 0 to 151, with higher scores reflecting a higher quality of marriage (Spanier, 1976). The mean score for married couples is 114.8, and 70.7 for divorced couples. The DAS also includes four subscales: consensus, which measures the level of agreement on areas important to couple functioning, relationship satisfaction, cohesion, and affectional expression (Spanier). The DAS was also used in this study, given that it has used in previous studies on EFT (Makinen \& Johnson, 2006), and a Cronbach's alpha of .96. The Trust Scale measures three elements that make up trust in a relationship: faith, dependability, and predictability, and has an overall Cronbach's alpha of .81. Although the three elements of the Trust Scale can be used as subscales, the current study focused on the overall score.

\subsection{Procedure}

After responding to the flyers and newspaper advertisements, all participants were screened to participate in the study, which involved a brief interview and risk assessment, as well as completion of written assessments. Participation required scoring 80 or above on the Dyadic Adjustment Scale, indicating the couple is not severely distressed (Makinen \& Johnson, 2006). Each participant also completed the Trust Scale. Exclusion criteria also included all participants denying any past or present emotional, sexual, or physical abuse in their relationships, and denying any current suicidal or homicidal gestures, ideation, or intent for themselves or their partners. None of the participants were excluded based on those factors. One couple was screened out due to having previously received couple therapy from the facilitator of the relationship class.

Every participant who remained after the screening process above was then given a choice to either attend the relationship class and read the book, or read the book at home without participation in the class, which consisted of eight two-hour sessions completed over the course of ten weeks. Class participants also read the book and completed homework assignments between the sessions. Each week covered a different aspect of couple functioning, and followed the content and structure described in the facilitator's guide (Johnson, 2010). At the beginning of each session, there was a short didactic presentation by the facilitator, class discussion, and a review of the homework. This was followed by group viewing of videotaped couples engaging in the conversations outlined in the book, as well as a group discussion about the video clips. Each couple in the class then engaged in dyadic exercises related to the topics for that session, which were then discussed with the other class members. Participants who chose to only read the book at home completed it over the same ten-week period. Participants then completed the Dyadic Adjustment Scale and the Trust Scale again. 


\subsection{Design and Analysis}

The study was a non-random two-group pre-post design. The independent variables were time and the groups. 2 $\times 2$ repeated ANOVAs were completed for each DV, which consisted of dyadic adjustment and trust. The four sub-scales of the Dyadic Adjustment Scale were also included. Between-subjects factors were the class versus the book only. These were compared to each other in order to discover possible additional effects of attending a class in addition to reading a book at home. Data from an additional couple was also removed as an outlier due to extremely high pre-test scores on the DAS, giving them little to no room for improvement.

\section{Results}

The main results of the study are presented in Table 1.

Due to the difference in the pre-test means between the groups, a post-hoc analysis was conducted. Restricting the range of pre-test scores to make the means more comparable led to the book group mean changing to 111.57 , and the class group mean changing to 110.71. Post-test scores remained consistent with the original analysis, with the book group mean improving to 122.71 , and the class group mean to 112.0.

\section{Discussion}

This study initially asked whether or not attending a relationship course, in addition reading a self-help book, would result in more positive change for couples than reading the book alone. The null hypothesis was that there would be no difference between the two interventions, and that any effects would be due to time. At pre-test, participants who chose to participate in the class had on average a lower dyadic adjustment than the book group (106.8 compared to 116.8). According to Spanier (1976), the national average for married couples is 114.8, which suggests that couples who chose to read the book at home without coming to the class were at about an average level of adjustment, and those who came to the class were at a somewhat below average level. At post-test, the class group had not changed significantly in either direction, with a score of 105.7 , and the book group improved to 125.1, which is near the cutoff for reliable change (Jacobson \& Truax, 1991). Given that both groups read the book, and that those who did not attend the class improved more, results demand further discussion and questions.

Looking at one of the subscales of the DAS, the class group experienced a slight decrease in the area of consensus, or level of agreement on various issues in the relationship, from 47.8 to 46.2, and the book group increased from 51.4 to 54.2. Although neither of these changes is great enough to be clinically reliable, the difference is worth noting for future studies. Perhaps talking about relationship challenges around other couples leads to comparison with other couples and greater disagreement in relationships. Issues that the couple has "shelved" in their relationship may be brought up, which the class format cannot effectively address. Reading the book alone may not "stir the pot" in the same manner.

Notably, the class group also came in with a slightly lower level of trust in their relationships $(\mathrm{M}=1.88)$ than the book group $(M=2.05)$. At post-test, there was slightly more trust in the book group $(M=2.36)$ than the class group $(\mathrm{M}=1.81)$, although the difference is not statistically or clinically significant for either group. To further address this issue, the first post-hoc analysis involved restricting the range of the pre-test DAS to make them more comparable. As discussed above, the book group still improved much more than the class group.

Table 1. Pre- and post-test results of class and book-group interventions.

\begin{tabular}{ccc}
\hline & Pre-test & Post-test \\
\hline DAS: Class & $106.8(\mathrm{SD}=8.78)$ & $105.7(\mathrm{SD}=15.0)$ \\
DAS: Book only & $116.8(\mathrm{SD}=8.8)$ & $125.1(\mathrm{SD}=10.16)$ \\
Trust: Class & $1.88(\mathrm{SD}=0.73)$ & $1.81(\mathrm{SD}=0.84)$ \\
Trust: Book only & $2.05(\mathrm{SD}=0.62)$ & $46(\mathrm{SD}=0.58)$ \\
Consensus ${ }^{*}$ Class & $47.8(\mathrm{SD}=4.37)$ & $46.2(\mathrm{SD}=4.47)$ \\
Consensus: Book only & $51.4(\mathrm{SD}=4.35)$ & $54.2(\mathrm{SD}=5.47)$
\end{tabular}

Note: Sig. at $p=.03$. ${ }^{*}$ Consensus subscale of the DAS measures the degree of agreement on various issues in the relationship. 
The findings suggest that couples who are not as satisfied may not benefit as much from relationship enhancement education, and in some cases may even be harmed by it. This issue is a crucial one, given that Johnson (2008) states that the book meant for all couples, whether they are satisfied or not, and at least one study has found that contrary to popular belief, highly distressed couples often seek out marital education, along with more satisfied couples (DeMaria, 2005). It is possible that although the book Hold Me Tight may be useful for improving relationships outside of therapy (Dorian, 2009), it may not produce positive change for couples who are not very satisfied with their relationships. This reasoning is also supported by Gottman (1999), who suggested that unhappy couples may use communication skills and "process-talk" to escalate during conflict, rather than repair. In a sense, education may give them more to disagree about. Perhaps these couples who desire to participate in the Hold Me Tight Program would be better suited in seeing an emotionally focused couple therapist, leaving relationship enhancement education to those who are already experiencing a relatively satisfied marriage.

\section{Conclusion}

Due to the small sample size, and the lack of random assignment, the findings are limited to preliminary status. It is also possible that the dependent variables did not capture the experience of the participants. For example, many of the class participants commented on how the class had helped their relationships, and expressed desire for similar classes in the future. Future quantitative research may clarify the current findings on the effectiveness of the interventions, and qualitative research may uncover participants' experiences. Results of present study, however, provide clear direction and a base from which to build future evaluations of relationship education.

\section{References}

Bodenmann, G., \& Shantinath, S. D. (2004). The Couples Coping Enhancement Training (CCET): A New Approach to Prevention of Marital Distress Based upon Stress and Coping. Family Relations, 53, 477-484. http://dx.doi.org/10.1111/j.0197-6664.2004.00056.x

Bout, J., Sytema, S., \& Rankin, J. (2008). The Monster in between: Working with Couples in Intensives Group Treatment. Journal of Family Psychotherapy, 19, 157-169. http://dx.doi.org/10.1080/08975350801904981

Chambless, D. L., \& Ollendick, T. H. (2001). Empirically Supported Psychological Interventions: Controversies and Evidence. Annual Review of Psychology, 52, 685-716. http://dx.doi.org/10.1146/annurev.psych.52.1.685

Crawford, M. (2004). Mars and Venus Collide: A Discursive Analysis of Marital Self-Help Psychology. Feminism \& Psychology, 14, 63-79. http://dx.doi.org/10.1177/0959353504040305

Cummings, E. M., Faircloth, W. B., Mitchell, P. M., Cummings, J. S., \& Schermerhorn, A. C. (2008). Evaluating a Brief Prevention Program for Improving Marital Conflict in Community Families. Journal of Family Psychology, 22, $193-202$. http://dx.doi.org/10.1037/0893-3200.22.2.193

Daire, A. P., Harris, S. M., Carlson, R. G., Munyon, M. D., Rappleyea, D. L., Beverly, M. G., \& Hiett, J. (2012). Fruits of Improved Communication: The Experiences of Hispanic Couples in a Relationship Education Program. Journal of Couple \& Relationship Therapy, 11, 112-129. http://dx.doi.org/10.1080/15332691.2012.666498

DeMaria, R. M. (2005). Distressed Couples and Marriage Education. Family Relations, 54, 242-253.

Dorian, M. (2009). Hold Me Tight [Review of the Book Hold Me Tight: Seven Conversations for a Lifetime of Love, by S. M. Johnson]. The Family Psychologist, 25.

Doss, B. D., Rhoades, G. K., Stanley, S. M., \& Markman, H. J. (2009). Marital Therapy, Retreats, and Books: The Who, What, When, and Why of Relationship Help-Seeking. Journal of Marital and Family Therapy, 35, 18-29. http://dx.doi.org/10.1111/j.1752-0606.2008.00093.x

Ellis, A. (1993). The Advantages and Disadvantages of Self-Help Therapy Materials. Professional Psychology: Research and Practice, 24, 335-339. http://dx.doi.org/10.1037/0735-7028.24.3.335

Gardner, S. P., Giese, K., \& Parrott, S. M. (2004). Evaluation of the “Connections: Relationship and Marriage” Curriculum. Family Relations, 53, 521-527. http://dx.doi.org/10.1111/j.0197-6664.2004.00061.x

Gottman, J. M. (1999). The Marriage Clinic: A Scientifically Based Marital Therapy. New York: W.W. Norton \& Company.

Halford, W. K., Moore, E., Wilson, K. L., Farrugia, C., \& Dyer, C. (2004). Benefits of Flexible Delivery Relationship Education: An Evaluation of the Couple CARE Program. Family Relations, 53, 469-476. http://dx.doi.org/10.1111/j.0197-6664.2004.00055.x

Halliday, G. (1991). Psychological Self-Help Books: How Dangerous Are They? Psychotherapy: Theory, Research, Practice, Training, 28, 678-680. http://dx.doi.org/10.1037/0033-3204.28.4.678 
Hawkins, A. J., Blanchard, V. L., Baldwin, S. A., \& Fawcett, E. B. (2008). Does Marriage and Relationship Education Work? A Meta-Analytic Study. Journal of Consulting and Clinical Psychology, 76, 723-734. http://dx.doi.org/10.1037/a0012584

Jacobson, N. S., \& Truax, P. (1991). Clinical Significance: A Statistical Approach to Defining Meaningful Change in Psychotherapy Research. Journal of Consulting and Clinical Psychology, 59, 12-19. http://dx.doi.org/10.1037/0022-006X.59.1.12

Jakubowski, S. F., Milne, E. P., Brunner, H., \& Miller, R. B. (2004). A Review of Empirically Supported Marital Enrichment Programs. Family Relations, 53, 528-536. http://dx.doi.org/10.1111/j.0197-6664.2004.00062.x

Johnson, S. (2008). Hold Me Tight: Seven Conversations for a Lifetime of Love. New York: Little, Brown and Company.

Johnson, S. (2010). The Hold Me Tight Program: Conversations for Connection. Ottawa, ON: International Centre for Excellence in Emotionally Focused Therapy.

Johnson, S., Hunsley, J., Greenberg, L., \& Schindler, D. (1999). Emotionally Focused Couples Therapy: Status \& Challenges (A Meta-Analysis). Journal of Clinical Psychology: Science and Practice, 6, 67-79.

Long, E. C. J., Angera, J. J., Carter, S. J., Nakamoto, M., \& Kalso, M. (1999). Understanding the One You Love: A Longitudinal Assessment of an Empathy Training Program for Couples in Romantic Relationships. Family Relations, 48, 235242. http://dx.doi.org/10.2307/585632

Mains, J. A., \& Scogin, F. R. (2003). The Effectiveness of Self-Administered Treatments: A Practice-Friendly Review of the Research. Journal of Clinical Psychology, 59, 237-246. http://dx.doi.org/10.1002/jclp.10145

Makinen, J. A., \& Johnson, S. M. (2006). Resolving Attachment Injuries in Couples Using Emotionally Focused Therapy: Steps toward Forgiveness and Reconciliation. Journal of Consulting and Clinical Psychology, 74, 1055-1064. http://dx.doi.org/10.1037/0022-006X.74.6.1055

Norcross, J. C., Santrock, J. W., Campbell, L. F., Smith, T. P., Sommer, R., \& Zuckermann, E. L. (2000). Authoritative Guide to Self-Help Resources in Mental Health. New York: The Guilford Press.

Norcross, J. C., Santrock, J. W., Campbell, L. F., Smith, T. P., Sommer, R., \& Zuckerman, E. L. (2003). Authoritative Guide to Self-Help Resources in Mental Health. New York: The Guilford Press.

Ooms, T., \& Wilson, P. (2004). The Challenges of Offering Relationship and Marriage Education to Low-Income Populations. Family Relations, 53, 440-447. http://dx.doi.org/10.1111/j.0197-6664.2004.00052.x

Pomeroy, E. C., Green, D. L., \& Van Laningham, L. (2002). Couples Who Care: The Effectiveness of a Psychoeducational Group Intervention for HIV Serodiscordant Couples. Research on Social Work Practice, 12, 238-252. http://dx.doi.org/10.1177/104973150201200203

Rempel, J. K., Holmes, J. G., \& Zanna, M. P. (1985). Trust in Close Relationships. Journal of Personality and Social Psychology, 49, 95-112. http://dx.doi.org/10.1037/0022-3514.49.1.95

Rosen, G. M. (1993). Self-Help or Hype? Comments on Psychology’s Failure to Advance Self-Care. Professional Psychology: Research and Practice, 24, 340-345. http://dx.doi.org/10.1037/0735-7028.24.3.340

Sells, J. N., Giordano, F. G., \& King, L. (2002). A Pilot Study in Marital Group Therapy: Process and Outcome. The Family Journal, 10, 156-166. http://dx.doi.org/10.1177/1066480702102005

Spanier, G. B. (1976). Measuring Dyadic Adjustment: New Scales for Assessing the Quality of Marriage and Similar Dyads. Journal of Marriage and Family, 38, 15-28. http://dx.doi.org/10.2307/350547

Sytema, S., \& Bout, J. (2006). Treatment Outcome of an Inpatient Group Therapy for Couples. Journal of Family Therapy, 28, 392-403. http://dx.doi.org/10.1111/j.1467-6427.2006.00360.x

Wetzler, S., Frame, S., \& Litzinger, S. (2011). Marriage Education for Clinicians. American Journal of Psychotherapy, 65, 311-336.

Wilson, D. M., \& Cash, T. F. (2000). Who Reads Self-Help Books? Development and Validation of the Self-Help Reading Attitudes Survey. Personality and Individual Differences, 29, 119-129. http://dx.doi.org/10.1016/S0191-8869(99)00182-8

Wood, N. D., Crane, D. R., Schaalje, G. B., \& Law, D. D. (2005). What Works for Whom: A Meta-Analytic Review of Marital and Couples Therapy in Reference to Marital Distress. The American Journal of Family Therapy, 33, 273-287.

http://dx.doi.org/10.1080/01926180590962147 
Scientific Research Publishing (SCIRP) is one of the largest Open Access journal publishers. It is currently publishing more than 200 open access, online, peer-reviewed journals covering a wide range of academic disciplines. SCIRP serves the worldwide academic communities and contributes to the progress and application of science with its publication.

Other selected journals from SCIRP are listed as below. Submit your manuscript to us via either submit@scirp.org or Online Submission Portal.
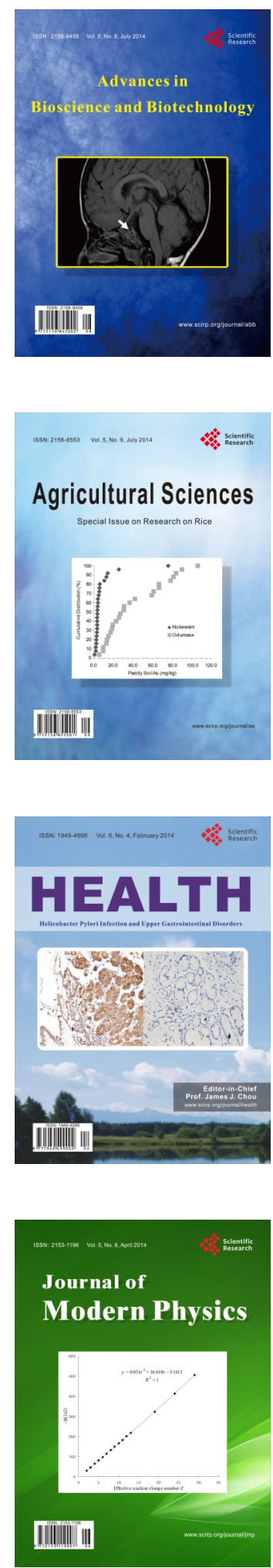
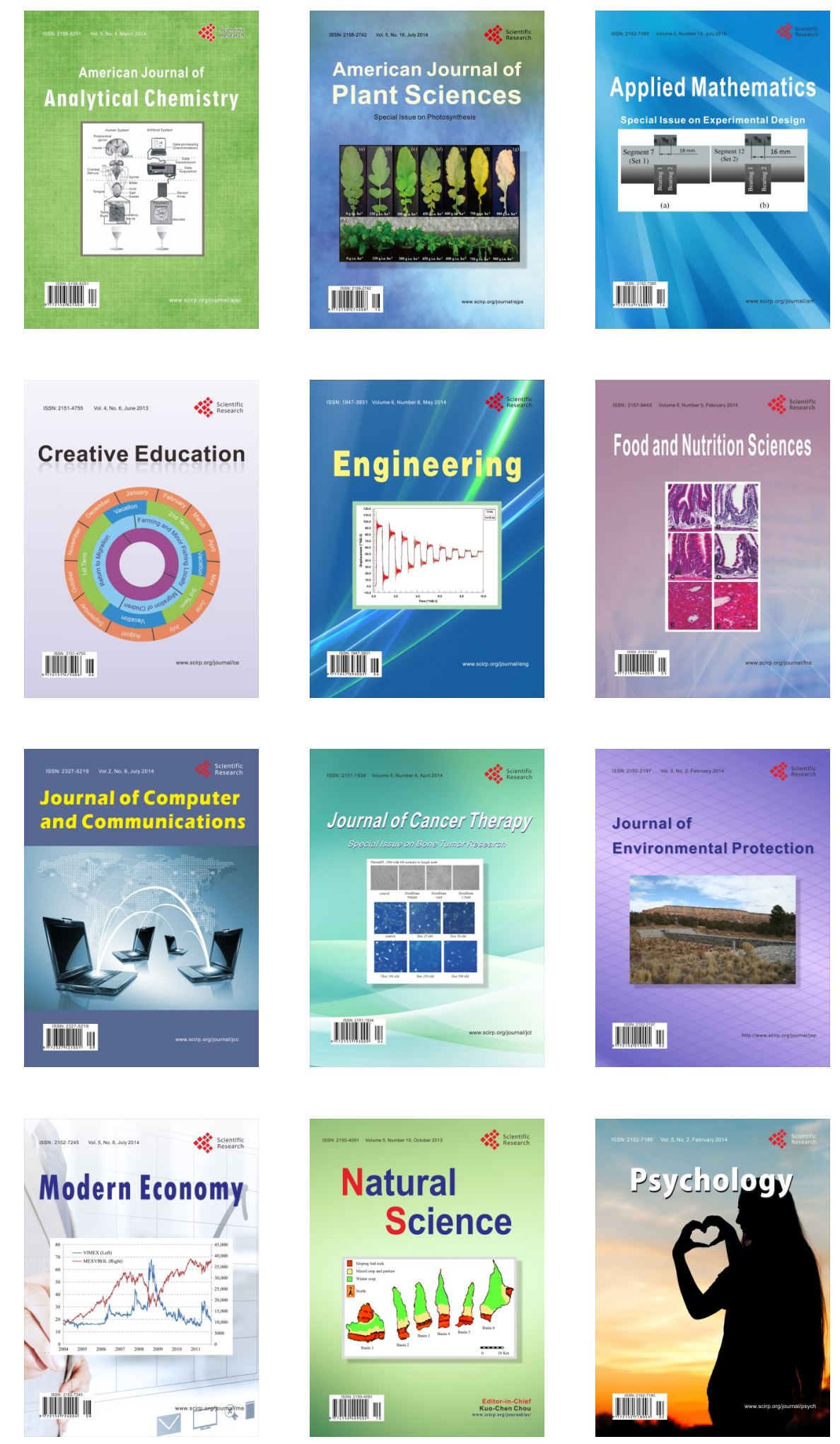